\title{
Locked Bridge Plating is a Suitable Option for Forearm Fractures Secondary to Civilian Low Velocity Gunshot Injuries
}

\author{
Vaidya Rahul*, Washington Austen and Ryan Bray \\ Detroit Medical Center, Heart Hospital, USA \\ *Corresponding author: Rahul Vaidya, Heart Hospital 5th Floor, USA
}

Received: 埲January 6, 2021

Published: 眥 January 18, 2021

\begin{abstract}
Introduction: The purpose of this retrospective study is to compare the outcomes of low velocity gunshot fractures of the forearm treated with minimal debridement and locked bridge plating to patients treated with formal debridement and conventional plating.

Materials and Methods: A 10 year IRB approved retrospective review of our national trauma database was conducted. Initial treatment consisted of wound care and sterile dressing. Forearm radiographs were acquired to determine bony involvement. All patients received intravenous antibiotics upon presentation to the emergency department and for a minimum of forty-eight hours after admission or operative intervention. Patients were placed into two categories of operative or nonoperative treatment. Those placed into operative treatment were further divided into the subcategories of formal debridement and plating or minimal debridement and plating.

Results: 94 patients were included in the study. 29 were treated nonoperatively and 65 were treated operatively. Of those 65 , 30 underwent minimal debridement and bridge plating and 35 were treated with formal debridement and bridge plating. All patient radiographs displayed fracture healing at latest follow-up with no evidence of infection or osteomyelitis. Nerve injuries were found among 15 patients and vascular injuries were present in 7.

Conclusions: Both methods of irrigation and debridement resulted in reliable osseous union with no instances of osteomyelitis. These results suggest that immediate locked bridge plating with minimal debridement is a suitable option for the treatment of forearm fractures following low velocity gunshot injuries.
\end{abstract}

Keywords: Irrigation; Debridement; Forearm; Gunshot; Fracture; Minimal

\section{Introduction}

There are 300,000 injuries and 30,000 hospitalizations from gunshot wounds annually in the United States [1-3] primarily from low-velocity handguns. These weapons produce less soft-tissue injury than high-velocity rifles or shotguns attributed to lower mass, velocity and energy transfer of the projectiles to surrounding tissues [4, 5]. Gunshot wounds of the forearm have been reported in several small series in the literature; however, no treatment guidelines backed by adequate scientific evidence exist. Prior studies with limited numbers have recommended debridement irrigation, antibiotics and compression plating for displaced fractures of one or both bones, and immobilization for undisplaced simple fractures of single bones. We feel that aggressive debridement and conventional compression plating may not be practical for these injuries which often have boney comminution but minimal soft tissue injury. A potential alternative is limited debridement and bridge plating. The purpose of this study is to compare the outcomes of low velocity gunshot fractures of the forearm treated with minimal debridement and locked bridge plating to patients treated with formal debridement and conventional plating. 


\section{Materials and Methods}

An IRB approved 10-year retrospective review of our hospital trauma database revealed one-hundred and one patient admitted to the hospital with forearm fractures following gunshot wound (2000-2010). Seven patients were excluded from the study as their injuries were the result of a high-velocity firearm, leaving ninety-four patients treated for gunshot wounds of the forearm with hospitalization. Patients who were discharged from the emergency room with gunshot wounds with or without fractures and patients who left the hospital against medical advice prior to treatment were not captured in this database. There were eightythree males and eleven females. The average age was 27.7 years with a range of 16-52 years. The average duration of follow-up of all patients was 27.3 months with a range of 9 to 105 months. Treatment was initiated with wound care by applying a sterile dressing in the emergency department. Forearm radiographs were acquired to determine bony involvement. Clinical suspicion of limb ischemia by physical exam was an indication for angiography. All patients received intravenous antibiotics upon presentation to the emergency department and for a minimum of forty-eight hours after admission or operative intervention. The initial antibiotic selected was cefazolin with or without gentamicin, and some patients with concomitant thoracic or abdominal injuries received additional antibiotics for greater time periods. Patients with non-displaced or minimally displaced fractures were treated non-operatively with local wound care, antibiotics, and casting. Displaced fractures were divided into 2 groups.

During the first 5 years 35 patients underwent aggressive debridement and irrigation of wounds, fracture stabilization using compression plating techniques when feasible and bridge plating when there was bone loss. Antibiotic cement spacers were placed where there was bone loss followed by delayed grafting using iliac crest bone. Eight were stabilized with initial external fixation followed by plating and 27 had immediate plate fixation. The second 5 years included 30 patients treated with open reduction and internal fixation (ORIF) with a bridge plating technique, limited irrigation and debridement of entry and exit wounds locally at the level of skin and subcutaneous tissue without debridement of bone. This was intended to minimize soft tissue stripping around the fracture site. Bullet fragments were not disturbed unless they were superficial and easily removed without further damaging the surrounding soft tissues. Entrance and exit wounds were not closed primarily. Patients with non-displaced or minimally displaced fractures (29) were treated non-operatively with local wound care, antibiotics and casting. These were often admitted for concomitant injuries and thus were picked up in our database. We reviewed all radiographic images obtained at presentation and during treatment. Fractures were classified as radius, ulna or both (Figure 1). The fracture location was noted whether they were proximal, midshaft or distal and if they were non-displaced or minimally displaced versus comminuted and displaced. Radiographic data were used to determine the status of fracture healing or hardware failure. Patients were examined in the clinic (Figure 2) to assess for fracture healing, infection, presence of deformity, sensory or motor deficits, and range of motion. Range of motion was classified as good ( $<10$ degrees flexion extension loss and $<25$ degree pronation/ supination loss), satisfactory $(<30$ degree flexion extension loss and $<50$ degree pronation/supination loss) or poor ( $>30$ degree flexion extension loss or $>50$ degree pronation/supination loss)
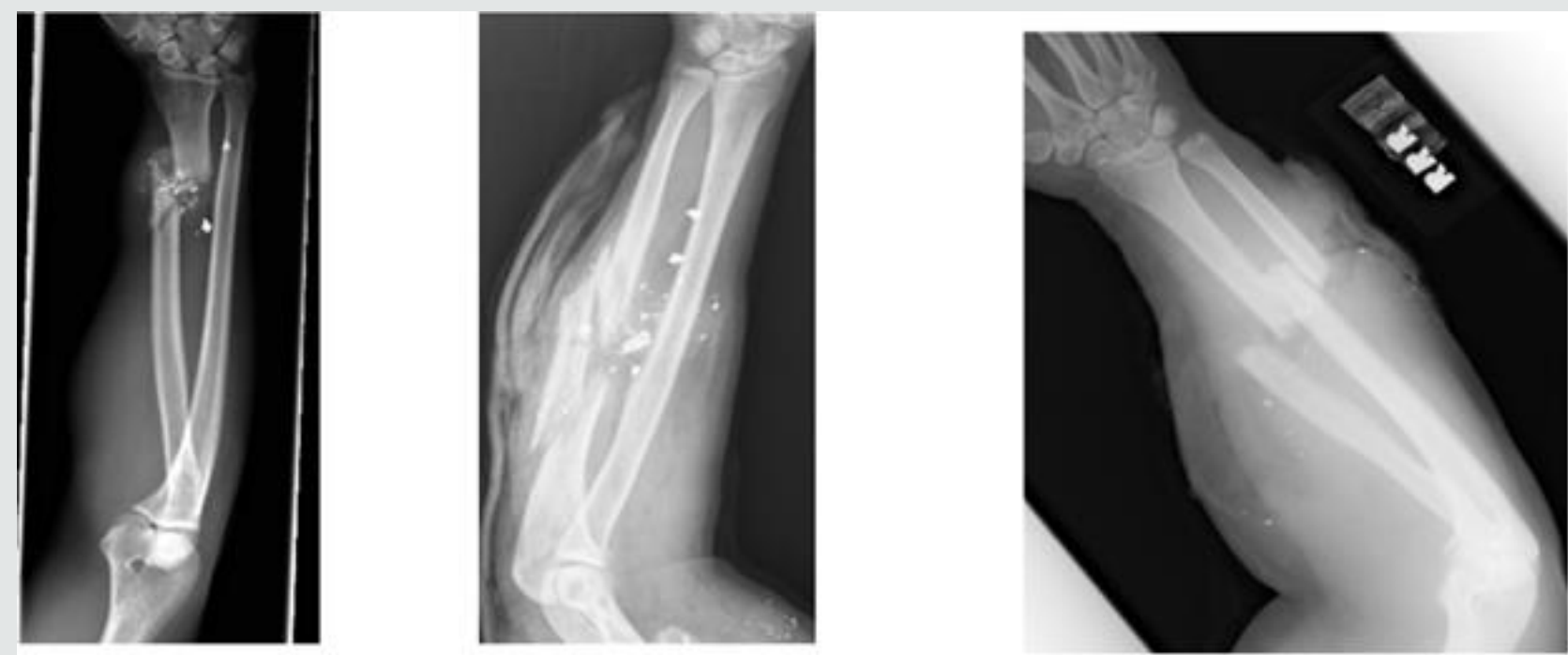

Figure 1: Radiographic images of, isolated radial, isolated ulna, and both bone fractures. 

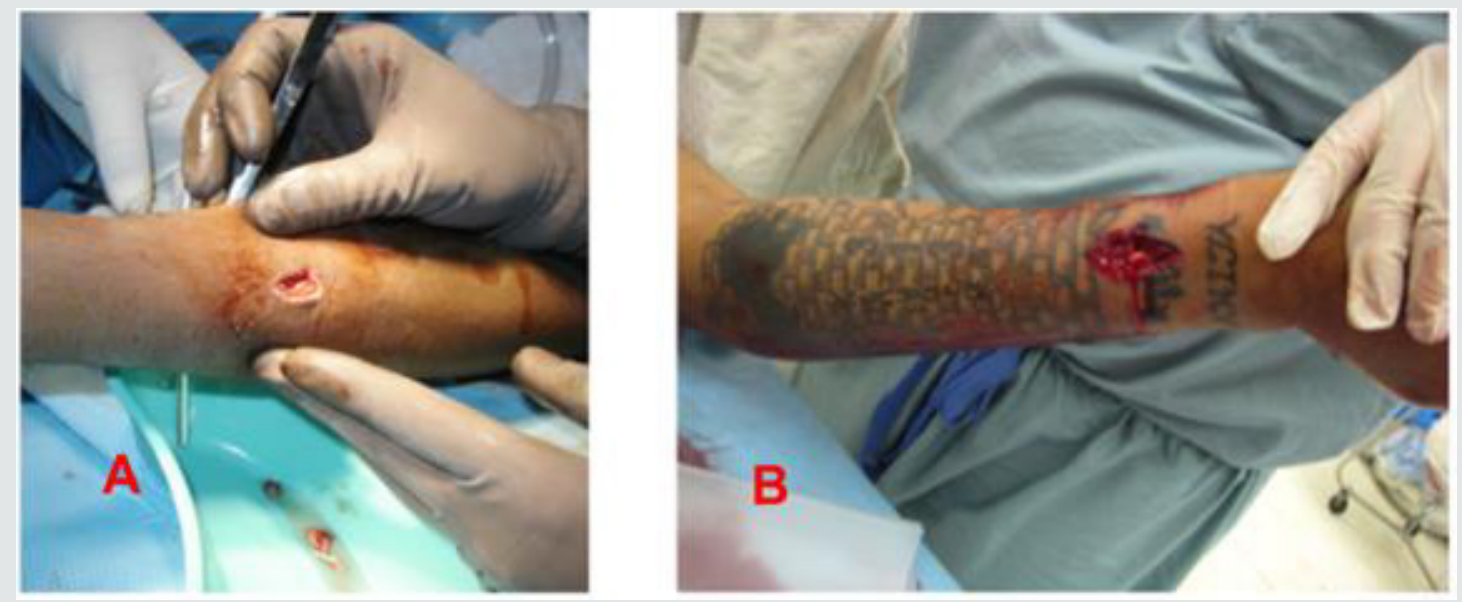

Figure 2: Example of soft tissue wound clinical examination.

\section{Results}

\section{Operative Treatment}

Sixty-five patients were treated operatively. Thirty patients underwent bridge plating and minimal debridement of the gunshot wounds without excision of only frankly necrotic tissue and minimal to no bone debridement and no bone grafting (Figure 3). Thirtyfive patients were treated with formal irrigation and debridement of the wounds and stabilization (Figure 4). Of the thirty patients with bridge plating and limited debridement twenty-nine patients displayed fracture healing at their latest follow up and one patient required revision surgery for delayed union. There were no signs of infection or osteomyelitis at final follow up. Of the thirty-five patients treated with more aggressive irrigation and debridement with fracture stabilization, seven patients were determined to have more extensive soft tissue injury requiring multiple surgeries and more aggressive debridement and eventual soft tissue coverage. Five of these seven required early bone grafting after original damage control surgery and prior to soft tissue reconstruction. All patients displayed radiologic evidence of healing at their latest follow up with no patient showing signs of infection or osteomyelitis.
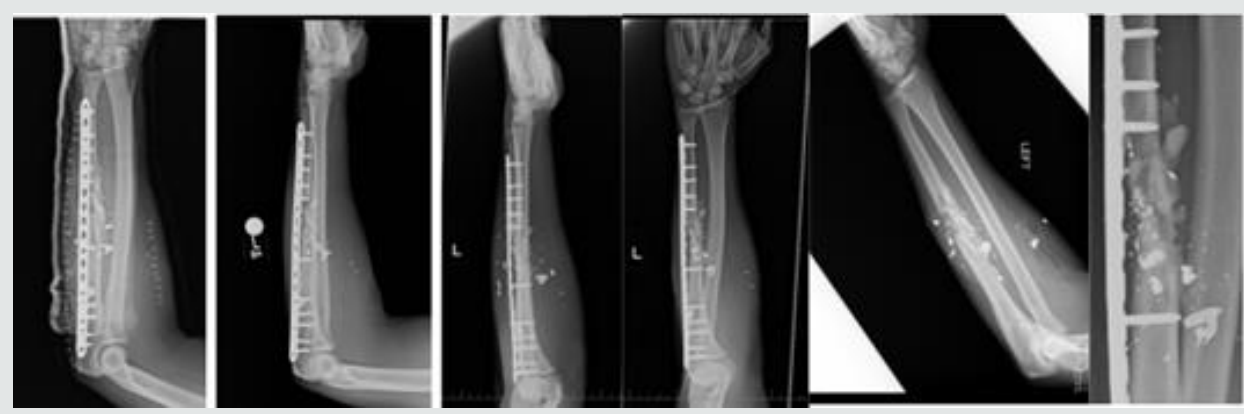

Figure 3: Example of patients treated with minimal debridement and locked bridge plating.
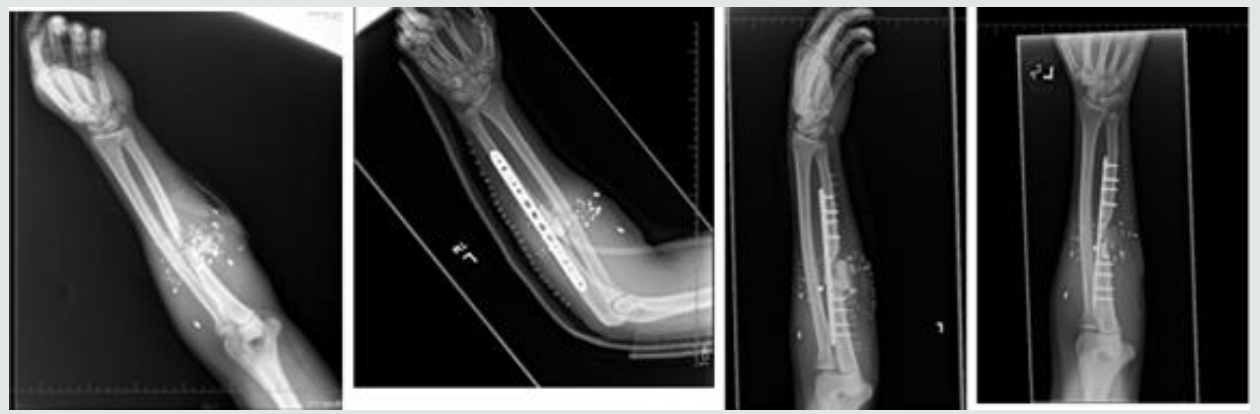

Figure 4: Example of patients treated with formal debridement and plating. 


\section{Non-Operative Treatment}

Twenty nine patients were treated non-operatively with local wound care and casting for forearm fractures. All patients had a single bone non-displaced or minimally displaced fracture. All patients displayed radiographic evidence of fracture healing at their latest follow up with no patient showing signs of infection or osteomyelitis. Range of motion in this subset was determined to be satisfactory or good at final follow up.

\section{Nerve Injuries}

There were fifteen patients with an associated nerve injury. The ulnar and median nerve were the most common nerves injured (six patients each) followed by the radial nerve in four patients and the palmar cutaneous nerve and anterior interosseous nerves in one patient each. Three patients had multiple nerve injuries. In seven patients the nerve injury resolved completely and in five patients a partial nerve deficit was observed. Three patients showed no recovery with one patient displaying a classical ulnar claw hand deformity.

\section{Vascular Injury}

Seven patients presented with signs of associated vascular injury of the forearm. There were four radial artery injuries and four ulnar artery injuries. One patient had both arteries injured and repaired. All patients had a viable limb on follow up. Three patients had nerve injury associated with vascular injury. One patient developed a compartment syndrome requiring fasciotomy.

\section{Discussion}

Early stabilization of forearm fractures is important after a gunshot injury and the management of the open wound and soft tissue injury is always an important consideration for surgical planning. In this study, we showed that minimal irrigation and debridement of the entrance and exit wounds is adequate for low velocity gunshot injuries to the forearm with minor visible soft tissue injury, and that bridge plating with minimal surgical dissection through the zone of injury is sufficient to achieve reliable union of these fractures. Dicpinigaitis, et al. showed that most non-displaced fractures of the radius or ulna can be effectively managed with casting al in their review of the literature addressing gunshot wounds to the extremities, but displaced fractures should be treated operatively with compression plating [4]. reported superior results in patients treated with delayed primary ORIF with displaced forearm fractures secondary to gunshot wounds [12]. In the same study, no patients treated by delayed ORIF went on to melanin or delayed union, but all patients did have decreased range-of-motion, particularly pronation and supination. Rodrigues, et al. recommended a treatment protocol involving early wound care and provisional stabilization followed by definitive treatment with internal fixation within one week [18-20]. In our review, thirty five patients were successfully treated with a more extensive soft tissue debridement with fracture stabilization, and thirty patients with comminuted and displaced fractures were effectively treated with local wound care followed by internal fixation with bridge plating.

Several studies have also examined the effectiveness of nonsurgical treatment in non-displaced or minimally displaced forearm fractures resulting from low-velocity firearms. Elstrom, et al. reported on fourteen patients that were treated with casting [12]. In eight non-displaced single bone fractures, seven had good outcomes. In six displaced fractures, closed reduction and casting lead to poor outcomes in four patients. Lenihan ,et al. reported on thirty-seven patients with civilian gunshot wounds to the radius and ulna [13]. Twenty-three patients with non-displaced fractures were treated by closed means with twenty-one showing good outcomes. However, in the fourteen patients with displaced fractures, the outcomes of the eight patients who had closed reduction were worse than the six patients treated surgically. Dickson, et al. prospectively evaluated patients with non-displaced fractures treated as outpatients with closed reduction and casting [3]. Only one patient in their study went on to delayed union [3]. also reported excellent results in patients of non-displaced fractures treated with closed reduction in a long arm cast, with seven of eight patients showing evidence of fracture healing and good functional outcome. The same study reported that four out of six patients with comminuted and displaced fractures treated with casting went on to malunion or delayed union resulting in a poor functional outcome. The authors concluded that closed reduction has satisfactory results in non-displaced fractures while displaced fractures require internal fixation to achieve superior outcomes. In our retrospective review we found similar results and agree that patients with minimally displaced or non-displaced extra-articular fractures can be adequately treated with closed reduction and casting without surgical debridement. We add to these findings that extensive surgical debridement can also be withheld with low risk of infection or nonunion after bridge plating for fracture stabilization.

Past studies have shown that bullets are not sterilized during discharge of the weapon and may act as a vector introducing pathogenic bacteria into the wound4. Controversy exists, however, as to the necessity of administering prophylactic antibiotics to this patient population. Patzakis, et al. demonstrated an infection rate of $13.9 \%$ in patients with open fractures resulting from gunshot wounds not treated with antibiotics and an infection rate of $2.3 \%$ in patients treated with cephalothin [7]. The study also showed no statistically significant difference in infection rate between the control group (13.9\%) and a group treated with penicillin and streptomycin (9.7\%) [7]. Conversely investigated the efficacy of antibiotics in a similar patient population and showed no significant difference in infection rate between the control group and the experimental group treated with at least twenty-four hours 
of intravenous cefazolin [2]. concluded in a prospective study that short-term intravenous antibiotics did not decrease the risk of infection [9]. recommended the use of prophylactic antibiotics in high-velocity and intra-articular injuries but did not support the use of prophylactic antibiotics for low-velocity injuries [10]. Howland and Ritchey in a retrospective analysis concluded that prophylactic antibiotics were unnecessary in the treatment of lowvelocity gunshot fractures [11-20]. In our study, all patients were treated with intravenous first generation cephalosporin antibiotics, and in some cases additional antibiotics to treat other concurrent injuries. As no patient in our review developed osteomyelitis even with a large subset undergoing limited debridement, we support the use of a first-generation cephalosporin for 48 hours in patients reporting with open forearm fractures secondary to low-velocity gunshot wounds.

We recognize the following limitations of our study. First, it is retrospective in nature and carries all the associated risks of bias. It is additionally possibly biased towards more severe injuries since all included patients were admitted for at least 48 hours. Patients with minor gunshot forearm injuries and treated as outpatients had variable antibiotic regimens or no antibiotics and were not captured in this database. Thirdly, the patient population of this study is small, although it is larger than previously published studies. Furthermore, we had difficulty in contacting patients in our study for longer term follow up.

\section{Conclusion}

Forearm fractures caused by low velocity gunshot wounds in a civilian setting are often comminuted single bone injuries with minor soft tissue injury. Both the aggressive and limited debridement regimens resulted in reliable osseous union and no instances of osteomyelitis. These results suggest that immediate locked bridge plating with minimal debridement is a suitable option for the treatment of forearm fractures following low velocity gunshot injuries.

\section{Acknowledgements}

Authors have no acknowledgements to report.

\section{Sources of Funding}

Authors report no sources of funding were utilized.

\section{References}

1. Cook A, Osler T, Hosmer D, Glance L, Rogers F, et al. (2017) Gunshot wounds resulting in hospitalization in the United States 2004-2013. Injury 48(3): 621-627.
2. Dickey RL, Barnes BC, Kearns RJ, Tullos HS (1989) Efficacy of Antibiotics in low-velocity gunshot fractures. J Orthop Trauma 3(1): 6-10.

3. Dickson K, Watson TS, Haddad C, Jenne J, Harris M, et al. (2001) Outpatient management of low-velocity gunshot-induced fractures. Orthopedics 24(10): 951-954.

4. Dicpinigaitis PA, Koval KJ, Tejwani NC, Kenneth A Egol, et al. (2006) Gunshot wounds to the extremities. Bulletin of the NYU Hospital for Joint Diseases 64(3\&4):139-155.

5. Bartlett CS, Helfet DL, Hausman MR, Strauss E (2000) Ballistics and gunshot wounds: effects on musculoskeletal tissues. J Am Acad Orthop Surg 8(1): 21-36.

6. Woloszyn JT, Uitvlugt GM, Castle ME (1988) Management of civilian gunshot fractures of the extremities. Clin Orthop Relat Res (226): 247 251.

7. Patzakis MJ, Harvey JP, Ivler D (1974) The role of antibiotics in the management of open fractures. J Bone Joint Surg Am 56(3): 532-541.

8. Knapp TP, Patzakis MJ, Lee J, P R Seipel, K Abdollahi, et al. (1996) Comparison of intravenous and oral antibiotic therapy in treatment of fractures caused by low-velocity gunshots. J Bone Joint Surg Am. 78(8): $1167-1171$

9. Geissler WB, Teasedall RD, Tomasin JD, Hughes JL (1990) Management of low velocity gunshot-induced fractures. J Orthop Trauma 4(1): 39-41.

10. Simpson BM, Wilson RH, Grant RE (2003) Antibiotic therapy in gunshot wound injuries. Clin Orthop Relat Res (408): 882-885.

11. Howland WS Jr, Ritchey SJ (1971) Gunshot fractures in civilian practice. An evaluation of the results of limited surgical treatment. J Bone Joint Surg Am 53(1): 47-55.

12. Elstrom JA, Pankovich AM, Egwele R (1978) Extra-artciular low-velocity gunshot fractures of the radius and ulna. J Bone Joint Surg Am 60(3): 335-341.

13. Lenihan MR, Brien WW, Gellman H, Itamura J, Kuschner SH, et al. (1992) Fractures of the forearm resulting from low-velocity gunshot wounds. J Orthop Trauma 6(1): 32-35.

14. Chapman MW, Mahoney M (1979) the role of early internal fixation in the management of open fractures. Clin Orthop Relat Res (138):120-131.

15. Duncan R, Geissler W, Freeland Ad, Savoie FH (1992) Immediate internal fixation of open fractures of the diaphysis of the forearm. J Orthop Trauma 6(1): 25-31.

16. Jones JA (1991) Immediate internal fixation of high-energy open forearm fractures. J Orthop Trauma 5(3): 272-279.

17. Moed BR, Kellam JF, Foster RJ, Tile M, Hansen Jr ST, et al. (1986) Immediate internal fixation of open fractures of the diaphysis of the forearm. J Bone Joint Surg Am 68(7): 1008-1017.

18. Rodrigues RL, Sammer DM, Chung KC (2006) Treatment of complex below-the-elbow gunshot wounds. Ann Plast Surg 56(2): 122-127.

19. Moed BR, Fakhouri AJ (1991) Compartment syndrome after low-velocity gunshot wounds to the forearm. J Orthop Trauma 5(2): 134-137.

20. Bowyer GW, Rossiter ND (1997) Management of gunshot wounds of the limbs. J Bone Joint Surg Am 79(6): 1031-1036. 
CC (P) This work is licensed under Creative

To Submit Your Article Click Here: $\quad$ Submit Article

DOI: $10.32474 /$ OSMOAJ.2021.04.000200

\begin{tabular}{l}
$\begin{array}{c}\text { Orthopedics and Sports Medicine } \\
\text { Open Access Journal }\end{array}$ \\
Assets of Publishing with us \\
- Global archiving of articles \\
- Immediate, unrestricted online access \\
- Rigorous Peer Review Process \\
- Authors Retain Copyrights \\
\hline Orthopedics And Sports Medicine: \\
Open Access Journal
\end{tabular}

